\title{
GREEN SYNTHESIS, CHRACTERISATION AND ANTIBCTERIAL ACTIVITIES OF TUNGSTEN, TIN AND LEAD NANOPARTICLES BYCUCURBITA MAXIMA (PUMPKIN) FLOWER EXTRACT
}

\author{
S. Nivetha ${ }^{a}$, Dr. K. Sathiyamoorthi ${ }^{a}$, Dr. S. DarlinQuine ${ }^{a^{*}}$ \\ aPG\&ResearchDepartment of Chemistry, Government arts college, Chidambaram, Tamilnadu, \\ India-608102 \\ *corresponding authour email:darlinmainzen728@gmail.com
}

\begin{abstract}
:
In this paper, a green synthetic route was developed to synthesize tungsten, tin and lead nanoparticles mediated by the Cucurbita maxima flower extract, Cucurbita is monoecious (unisexual flowers, with male and female on the same plant), bearing solitary actinomorphic flowers (10-20 cm across) that are open for a single day Cucurbita maxima was a traditional vegetable food for south Indian. The flower of Cucurbita maxima aqueous extract is analyzed for the phytochemical constituent. The synthesized nanoparticles are characterized by UV, FTIR, XRD and SEM with EDS. The synthesized three nanoparticles also screened by gram positive and negative bacterial strains.
\end{abstract}

Keywords: Green synthesis, WNPs, SnNPs, PbNPs, Characterization, Antibacterial activity

\section{INTRODUCTION}

Nanotechnology aims the production of very small sized particles that have nanoscale dimension [1-2]. A number of chemical and physical approaches are used to synthesize nanoparticles (NPs) with desired properties, but these methods are very expensive, harmful for the humans and environment, labor intensive, toxic and high amount of energy and pressure is required for their proper completion [3]. NPs are biologically produced by plants,algae, fungi, bacteria, diatoms and human cells. Plants are preferred among all the green synthesis routes for nanoparticles [4-5]. Characteristics of nanoparticles as well as their stability, size and shape are greatly affected by the temperature, concentration, pHand many other factors during the formation process[6]. Different kinds of NPs including gold, iron, zinc, silver, copper, platinum as well as oxides of metals and non-metals etc are formed from prokaryotes and eukaryotes [7]. Among all, Zn NPs are preferred because they can generate ROS and are good semiconductors [8-9]. Characteristics of $\mathrm{Zn}$ NPs depend on their size, concentration and shape [10]. Extracts of the plants are used as bioreductant and capping agent for producing NPs [11]. Phytomolecules [12] and secondary metabolites present in plants extract play vital roleduring nanoparticle synthesis [13-14]. Green synthesis is based on redox reaction, in which metal ions are reduced to stable NPs by the components of an organism or its extract. Although living organisms, such as algae, fungi, bacteria and plants, could synthesize NPs in vivo [15-19], plant extract-mediated, in vitro green synthesis ofNPs has gained popularity due to its simplicity, low cost, eco-friendly nature, and easiness to scaleup. Although plant extract-mediated green synthesis is a recent technology, a contrasting process has been used for the preparation of Bhasma (ash of metal) in Ayurveda, a traditional Indian medicine practiced for more than 2000 years. In the former, metal ions are reduced and stabilized asNPs[20-23] by the components of the extract (bottom-up approach); by contrast, in the latter, NPs are produced by the calcination of metal sheets (topdown approach), which are macerated withmedicinal plant extracts to obtain therapeutic potential. We report the green synthesis of tungsten, tin and lead nanoparticles mediated by tradition plant of Cucurbita maxima flower extract, characterization and also reported antimicrobial activities against three gram positive and three gram negative bacterial strains. 

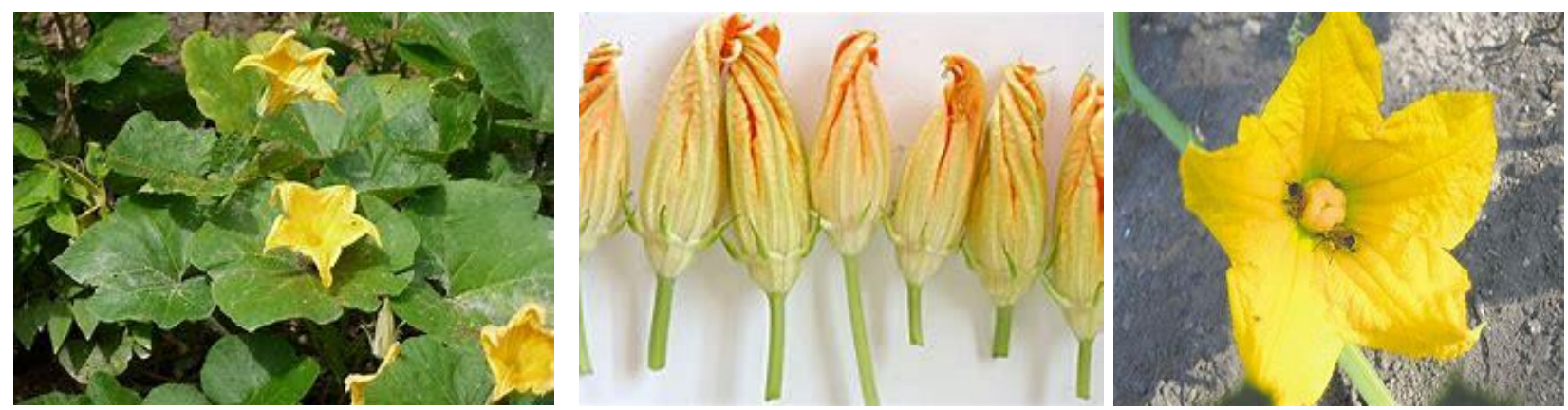

Figure:1:Images of Cucurbita maxima (Pumpkin)flowers

\section{Materials and Methods}

\subsection{Sample collection}

The fresh flower of Cucurbita maxima are collected early morning in winter season (November and December) from the C. Mutlur village of Chidambaram, Cuddalore district, Tamil Nadu, India

\subsection{Reagents}

All analytical grade chemical and solvents used in the sample preparation were purchased from local suppliers of Singma-Aldrich chemical company-Pondicherry, Precession scientific company-Trichy.

\subsection{Extraction}

Extraction from dried flower of Cucurbita maxima, these flowers are done using water as the extraction solvents. via direct hot extraction (DHE) method [24], $100 \mathrm{ml}$ of solvent with 100 gm of the sample (flower extract) in around bottomed flask was kept on a heating mantle covering at $60^{\circ} \mathrm{C}$ for two days followed by ensuing filtration by means of whatman filter paper \# 1. Then, the obtained filtrates were collected and dried with vacuum evaporator pending a rudimentary glutinous extract is obtained. Then, the collective supernatants are filtered and the filtrates are cooled and dried using hot air oven until a crude glutinous extract is obtained. After vanishing of organic solvents, these are stored at $-20^{\circ} \mathrm{C}$ till scrutiny.

\subsubsection{PHYTOCHEMICAL SCREENING}

The majority bioactive constituents of plants are steroids, tannins, flavonoid, alkaloids and phenolic compounds. To know the phyto-constituents of plants, the extracts are subjected to macro molecules and secondary metabolites analysis by using paradigm methods.

\subsubsection{PRELIMINARY QUALITATIVE ANALYSIS}

The preliminary qualitative analysis [25] of Cucurbita maxima (Pumpkin)flower extract, macro molecules was done as per the procedure given below.

\section{DETECTION OF CARBOHYDRATES}

A little amount of the extract is dissolved in $5 \mathrm{ml}$ of water and filtered. The filtrate is subjected to the subsequent test.

\section{Molisch's test}

All soluble carbohydrates give a purple colour when treated with molisch's reagent (alcohol, naphthol solution and conc. $\mathrm{H}_{2} \mathrm{SO}_{4}$ ) a soluble carbohydrates will form violet ring at the junction of the liquids.

\section{Fehling's test}

To a heated solution of extract mixture of equal parts of Fehling's solution A and Fehling's solution B was added drop by drop. Brick red precipitate shows the presence of reducing sugar.

\section{Barfoed's test}


To a portion of the extract, $2 \mathrm{ml}$ of Barfoed reagent is added and kept in boiling for less than 5 minutes. A coloured residue at the side's upper surface of the liquid is formed. Extract is hydrolyzed with dilute Hydrochloric acid for a few hours on water bath.

Benedict's test

To a portion of the extract, $5 \mathrm{ml}$ Benedict reagent is added and kept in boiling for less than 5 minutes. Reducing sugar indicates the brick red precipitate.

\section{DETECTION OF FREE AMINO ACIDS AND PROTEINS}

Little quantity of alcoholic and aqueous extract is dissolved in few $\mathrm{ml}$ of water and subjected to following test.

Millon's test

To the above extract Millon's reagent is added. Amino acids are confirmed by red colour formation.

\section{Biuret test}

To the above extract same volumes of $5 \% \mathrm{NaOH}$ and 3 or $1 \%$ of solution of $\mathrm{CuSO}_{4}$ are added. A violet colour formation indicates the amino acids present in the solution.

\section{Ninhydrin test} formation.

To the extract ninhydrin reagent is added. The amino acid is identified by violet colour

\section{DETECTION OF ALKALOIDS}

The small portion of the extract is dissolved in suitable solvent and each extract is stirred separately with only some drops of dilute $\mathrm{HCl}$ and filtered. The filtrate was examined for alkaloids by using following reagents.

\section{Mayer's reagent}

To the extract, potassium mercury iodide was added. Alkaloid indicates by formation of cream precipitate.

\section{Wagner's reagent}

To the extract, solution of iodine in potassium iodide is added. Formation of reddish brown colour, indicates the presence of alkaloid.

\section{Hager's reagent}

To the extract, saturated solution of picric acid and water was added. Formation of yellow precipitate indicates the presence of alkaloid.

\section{Dragandroff's reagent}

To the extract $\mathrm{KI}$ solution of $\mathrm{Bi}\left(\mathrm{NO}_{3}\right)_{2}$ was added. Formation of reddish brown colour evidenced the incidence of alkaloid.

\subsubsection{QUALITATIVE ANALYSIS OF SECONDARY METABOLITES DETECTION OF PHYTOSTEROLS \\ Libermann Burchard test}

The small amount of extract is dissolved in $2 \mathrm{ml}$ of $\mathrm{CHCl}_{3}$ in a dry test tube. Then 10 drops of $(\mathrm{AcO})_{2} \mathrm{O}$ and 2 drops conc. $\mathrm{H}_{2} \mathrm{SO}_{4}$ are added. The solution became red then blue and finally bluish green colour indicated the presence of steroids.

\section{Salkowasky test}

The few drops of extract are treated with $2 \mathrm{ml}$ of chloroform and equal volume of conc. $\mathrm{H}_{2} \mathrm{SO}_{4}$. Bluish red to cherry red colour is observed in chloroform layer; whereas the acid layer assumes marked green fluorescence evident the presence of steroids. 


\section{DETECTION OF PHENOLIC COMPOUNDS AND TANNINS}

The few drops of alcoholic and aqueous extract are treated in water and tested for the presence of phenolic compounds and tannins with $\mathrm{FeCl}_{3}$ solution (5\%), solution of gelatine containing $10 \% \mathrm{NaOH}, 10 \% \mathrm{~Pb}(\mathrm{OAc})_{2}$ and aqueous bromine water.

\section{DETECTION OF FLAVANOIDS}

Extract is treated with sodium hydroxide the formation of yellow colour, evident that the presence of flavone.

Extract is treated with concentrated sulphuric acid, the formation of yellow to orange colour, indicates the presence of flavones

\section{DETECTION OF TRITERPINOIDS}

\section{LibermannBurchard test}

The few amount of the extract is dissolved in $2 \mathrm{ml}$ of chloroform in a dry test tube. Then 10drops of acetic anhydride and 2drops of conc. $\mathrm{H}_{2} \mathrm{SO}_{4}$ are added. Formation of wine red colour indicates the presence of tri-terpenoids.

\section{DETECTION OF GLYCOSIDES Legal test}

Small amount of the extract is dissolved in pyridine and sodium nitro prusside solution is added to make alkaline. Pink colour reveal that the presence of glycosides.

\section{Baljet test}

To the extract, sodium picrate solution is added. Yellow to orange colour indicated the presence of glycosides.

\section{Borntrager's test}

The extract was mixed with dilute sulphuric acid and filtered. Then filtrate was shaken with chloroform and the chloroform layer was separated and added dilute ammonia. Pink red to violet colour indicates the presence of glycosides.

\section{DETECTION OF SAPONINS}

Foam Test

$1 \mathrm{ml}$ of the test solution is taken in a measuring cylinder. To this, $20 \mathrm{ml}$ of distilled water is added and shaken well.

\section{Hameolysis test}

The extract of the plant is spreaded over a glass slide to form a thin film layer on which a drop of human blood was placed and spreaded over the extract layer. After 30 minutes slide was examined under microscope for change in structure and shape of red blood cells. Control was always maintained to see the change in red blood cells structure for hemolysis.

\section{DETECTION OF FIXED OILS AND FATS}

Extracts are taken and they are pressed between filter paper and the paper is noted.

Few drops of $0.5 \mathrm{~N}$ alc. $\mathrm{KOH}$ are added to various extracts with few drops of phenolphthalein. The mixture is heated on a water bath for 1-2 hours. Table:2 shows the result of preliminary tests of Cucurbita maxima flower extract.

\subsection{Preparation of Cucurbita maxima flower extract for synthesis of nanoparticles}

Cucurbita maxima flower washed are several times with de-ionized water and tried five days in room conditions, then grained and powdered. A $20 \mathrm{~g}$ of powdered flower is taken in 250 
$\mathrm{mL}$ round bottomed flask and stirred with $100 \mathrm{~mL}$ de-ionized water, heated at $80^{\circ} \mathrm{C}$ for three minutes and filtered by using whatmann $1 \neq$ filter paper to get the extract. The filtrate is used in the further synthesis process.

\section{Table:1 Green Synthesis of WNPs, SnNPs and PbNPs}

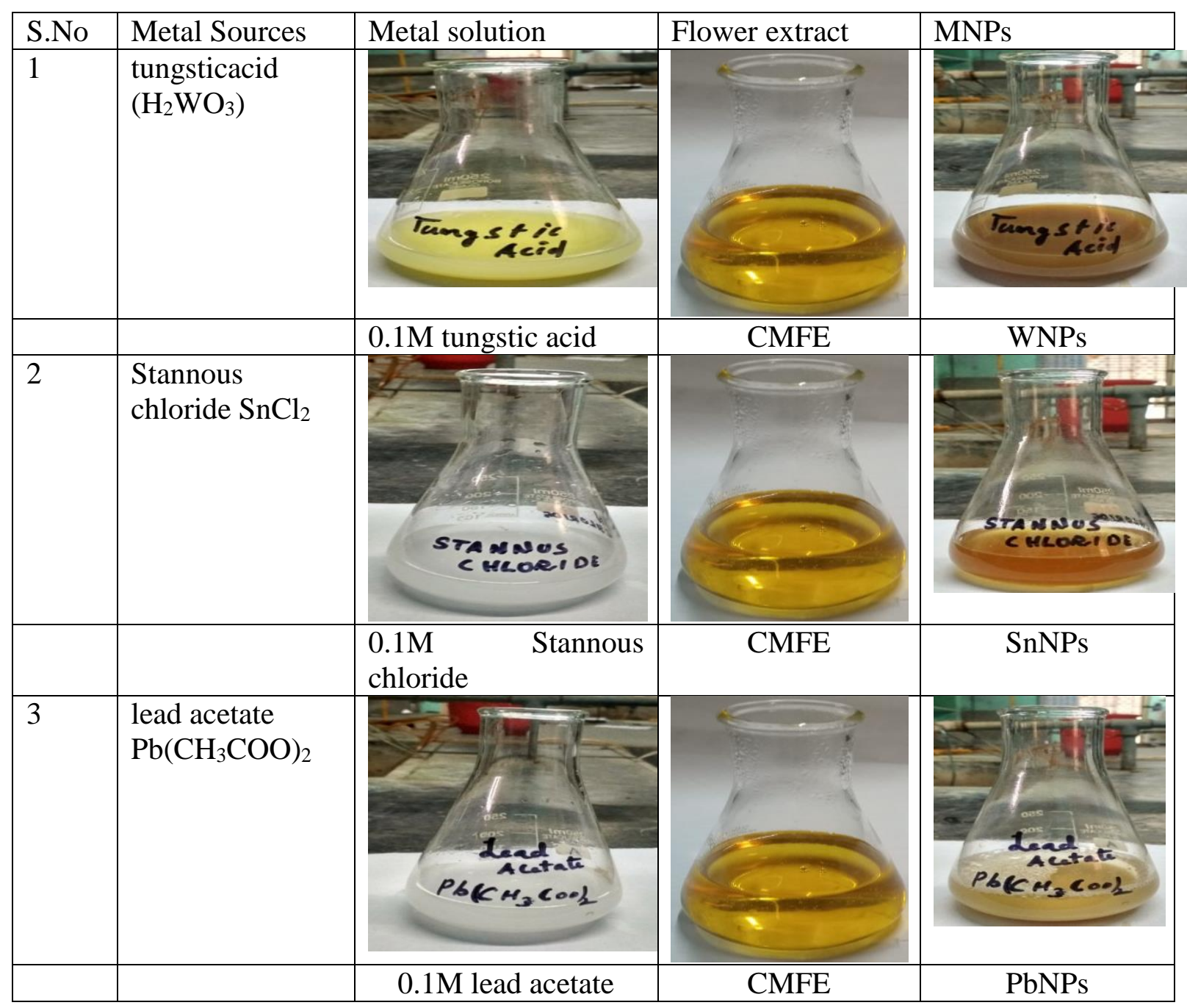

\subsubsection{Synthesis of tungsten nanoparticles (WNPs)}

Synthesis of WNPs is carried out by reducing tungstic acid (M.F: $\mathrm{H}_{2} \mathrm{WO}_{3}, \mathrm{M} . \mathrm{W}: 249.85$ $\mathrm{g} / \mathrm{mol}$ ) using Cucurbita maxima flower extract (CMFE). To achieve this purpose, $100 \mathrm{~mL}$ of saturated solution of tungstic acid is steadily mixed with $10 \mathrm{~mL}$ of Cucurbita maxima flower extract (CMFE). The colour of the solution turns from pale yellow to chocolate brown in colour forming tungsten nanoparticles. (Table:1). Further, obtained suspension is transferred to $250 \mathrm{~mL}$ separating funnel to collect the suspended enriched part, the suspended enriched part is centrifuged at $4000 \mathrm{rpm} / 20 \mathrm{~min}$. Supernatant is discarded and pellet containing WNPs is carefully washed 3 times with distilled water to remove unwanted materials. The obtained powder assumed as WNPs [26] is incubated at $\sim 100{ }^{\circ} \mathrm{C}$ until the water evaporated completely. Finally, WNPs were systematically characterized. 


\subsubsection{Synthesis of tin nanoparticles (SnNPs)}

For the fabrication of SnNPs by reducing stannous chloride using Couropita maxima flower extract (CMFE). To achieve this intention, $100 \mathrm{~mL}$ of homogenous solution of stannous chlorideis steadily mixed with $10 \mathrm{~mL}$ of Couropita maxima flower extract (CMFE), followed by continuous heating $\left(70^{\circ} \mathrm{C}\right)$ and stirring at $500 \mathrm{rpm}$ for $2 \mathrm{~h}$ in a magnetic stirrer with heating instrument, to achieve precipitate containing final solution (Table:1). The white colour reactant solution is turn to golden yellow in colour. The obtained brown colour solution was centrifuged at $4000 \mathrm{rpm} / 20 \mathrm{~min}$. Supernatant was discarded and pellet containing SnNPs [27] is carefully washed 3 times with double distilled water (DDW) to remove uninvolved phytoconstituent and other chemicals. The obtained wet precipitate is dried, collected and stored the airtight clicklock tube. Finally, SnNPs are methodically characterized.

\subsubsection{Synthesis of Leadnano particles (PbNPs)}

The synthesis of lead nanoparticles (PbNPs) carried out by, $100 \mathrm{~mL}$ of $0.1 \mathrm{M}$ of lead acetate solution is taken in a $250 \mathrm{ml}$ conical flask. Then, $10 \mathrm{ml}$ of Cucurbita maxima flower extract was added drop wise into lead acetate solution under continuous stirring for $30 \mathrm{~min}$ at the room temperature, the milky white solution of lead acetate is turn to pale pinkish in colour [28]. The resultant residue is filtered by using whattman $1^{\neq}$filter paper, the precipitate is washed several times in double distilled water, finally obtained the glittering crystalline product. The obtained final product is dried and characterized.

\section{RESULTS AND DISCUSSION}

\subsection{Phytochemical analysis}

\subsubsection{Yield of extraction} equation:

The yields of dried extract based on their dry weights are calculated using the following $\%$ Yield $(\mathrm{g} / 100 \mathrm{~g}$ of arid plant material $)=\left(\mathrm{W}_{1} / \mathrm{W}_{2} \times 100\right)$

Where, $\mathrm{W}_{1}$ was the weight of the extract after the evaporation of solvent and $\mathrm{W}_{2}$ was the weight of the dry plant material. The yield of aqueous extract of Cucurbita maxima flower is $4.28 \%$

\subsubsection{PRELIMINARY PHYTOCHEMICAL ANALYSIS}

The preliminary phytochemical study [31-32] of aqueous extract of Cucurbita maxima flower is conceded elsewhere to characterize the chemical constituents present in the extracts following standard procedures.

The results obtained from qualitative phytochemical analysis revealed the presence of biomolecules like carbohydrate, fats along with other important secondary metabolites like alkaloids, flavonoids, spaonins, phenols and steroids, which are known for their varied pharmaceutical roles. The use of preliminary data obtained was extended to extract the relevant biomolecules from the aqueous extract of Cucurbita maxima flower. The results of preliminary phytochemical analysis in Table: 2 
Table: 2 Phytochemical constituents of extract of Cucurbita maxima flower

\begin{tabular}{|c|c|c|c|c|c|c|}
\hline S.No & Phytoconstituent & Water & $\begin{array}{c}\text { Ethyl } \\
\text { alcohol }\end{array}$ & Benzene & Methanol & $\mathrm{CHCl}_{3}$ \\
\hline 1 & Carbohydrates & + & - & + & + & + \\
\hline 2 & Protein & - & - & + & - & + \\
\hline 3 & Glycosides & + & - & - & + & - \\
\hline 4 & Flavonoids & + & + & - & + & + \\
\hline 5 & Alkaloids & - & - & + & + & - \\
\hline 6 & Fixed oil/ Fat & + & - & + & - & + \\
\hline 7 & Spaonins & - & - & - & + & + \\
\hline 8 & Tannis & - & + & + & - & - \\
\hline 9 & Phenols & + & - & - & + & + \\
\hline 10 & Steriods & + & + & + & - & + \\
\hline
\end{tabular}

(+) indicate the existence of phytoconstituents

(-) indicate the nonexistence of phytoconstituents

\subsection{Characterization}

\subsubsection{UV-Vis Spectroscopy analysis}

Formation of nanoparticles is generally determined by optical properties which is one of the main criteria for their synthesis. Free electrons in the nanoparticles are excited by visible light and transmitted to a higher energy state, but the electron is wobbly in an excited state and returns to the base energy level and as a result a photon is emitted. Concurrently resonance frequency of surface plasmon in the metallic nanoparticles depends on shape, size and environment maintained during blend of nanoparticles. The UV-Vis spectrum of tungsten nanoparticles (Figure 2a) gave absorbance peaks around $385.5 \mathrm{~nm}$ and it showed strapping band at this wavelength. The spectrum figure $3 \mathrm{a}$ has shown maximum absorption around $334 \mathrm{~nm}$ for tin nanoparticles and lead nanoparticles figure $4 \mathrm{a}$ have shown in absorption peak at 330nm.

\subsubsection{FT-IR Spectroscopy analysis}

FTIR is applied in order to investigate possible biomolecules bearing different functional groups responsible for reduction, capping and efficient stabilization of newly synthesized tungsten nanoparticles (Figure.2b). The absorption bands at 3440, 1596, 1459, 874 and $487 \mathrm{~cm}^{-1}$ were observed. The strong peaks at $3440 \mathrm{~cm}^{-1}$ correspondes to hydroxyl group, $\mathrm{H}$-bonded $\mathrm{OH}$ stretches. The band at $2498 \mathrm{~cm}^{-1}$ was attributed to methyl $\mathrm{CH}$ asym/sym stretches and $487 \mathrm{~cm}^{-1}$ has represented $\mathrm{W}-\mathrm{O}$ stretching vibrations. The strong band at $1420 \mathrm{~cm}^{-1}$ is due to $\mathrm{COO}^{-}$ symmetric stretching and the carboxylate ion is responsible for the reduction of tungstic acid to W-O nanoparticles, which is confirmed by the reduced intensity of $1420 \mathrm{~cm}^{-1}$ band.

FTIR spectrum of green synthesized SnNPs. The band between $420 \mathrm{~cm}^{-1}$ can be assigned to $\mathrm{Sn}-\mathrm{O}$. The peak located at 728,880 , and $2390 \mathrm{~cm}^{-1}$ can be assigned to aromatic $\mathrm{CH}_{2}$ out of plane bending [63-68], aromatic ring stretching of cyclic compound, respectively (Figure 3b). The weak absorption at $3490 \mathrm{~cm}^{-1}$ denotes $\mathrm{N}-\mathrm{H}$ stretching vibration of the secondary amine. The strong band at $1440 \mathrm{~cm}^{-1}$ is due to $\mathrm{COO}^{-}$symmetric stretching and the carboxylate ion is responsible for the reduction of stannous chloride to $\mathrm{Sn}-\mathrm{O}$ nanoparticles, which is confirmed by 

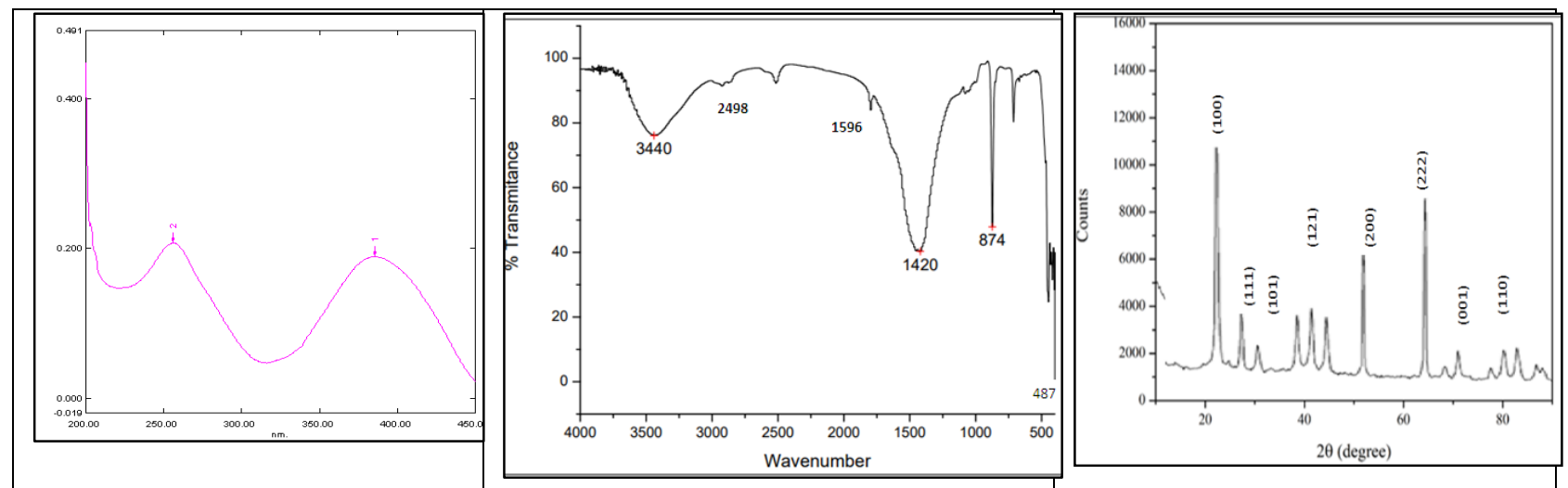

Figure:2 (a) UV (b)FTIR(c)XRD spectrum images of WNPs
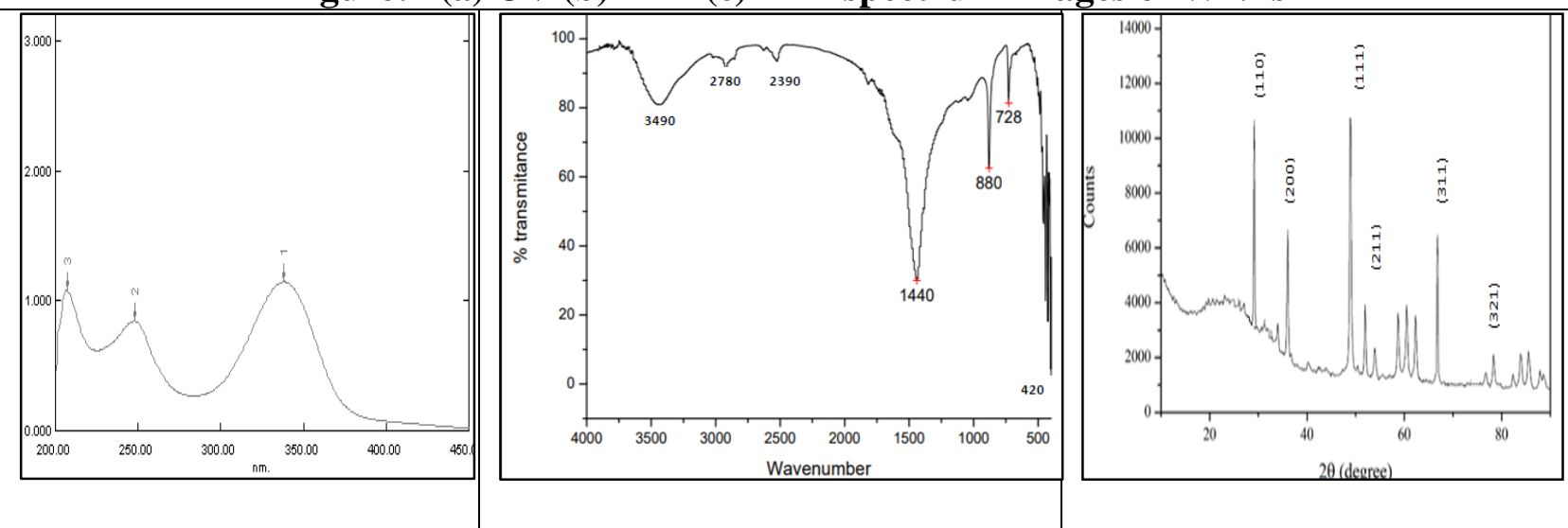

\section{Figure:3 (a) UV (b)FTIR(c)XRD spectrum images of SnNPs}
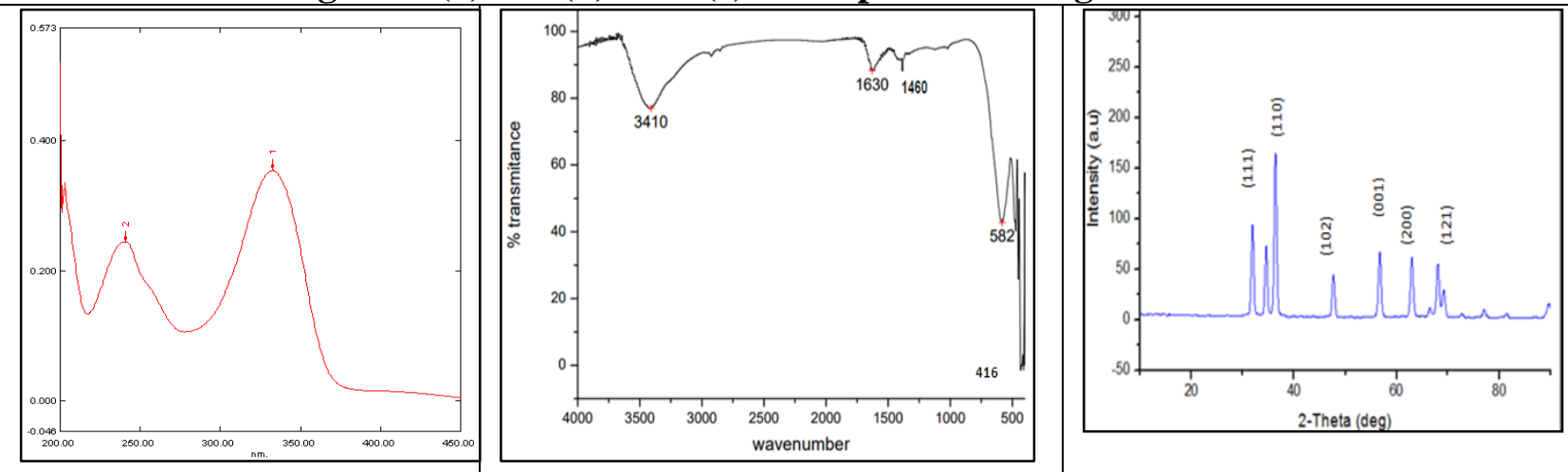

Figure:4 (a) UV (b)FTIR(c)XRD spectrum images of PbNPs

The reduction of intensity of $1440 \mathrm{~cm}^{-1}$ band. FTIR spectra for the lead nanoparticles are appeared in figure $4 \mathrm{~b}$. The strong band at $416 \mathrm{~cm}^{-1}$ demonstrates the nearness of $\mathrm{Pb}-\mathrm{O}$ extending and furthermore the band at $582 \mathrm{~cm}^{-1}$ shows the nearness of oxides. These two pinnacles are sharp and is affirmed that the last item is the nearness of lead and oxide.The weak band at 1460 $\mathrm{cm}^{-1}$ is due to $\mathrm{COO}^{-}$symmetric stretching and the carboxylate ion is responsible for the strong reduction of lead acetate to $\mathrm{Pb}-\mathrm{O}$ nanoparticles, which is confirmed by the reduction of intensity of $1460 \mathrm{~cm}^{-1}$ band. The yield of the PbNPs is very high compared with WNPs and SnNPs. 


\subsubsection{XRD analysis}

X-ray diffraction (XRD) studies are carried out to confirm the synthesis of WNPs and characterize crystallinity and the phase pattern of synthesized tungsten nanoparticles. It was observed that $2 \theta$ (in degrees) are in the range of 28.4 to $66.5^{\circ} \mathrm{C}$ (Figure. $2 \mathrm{c}$ ). The said $2 \theta$ morals of peaks are in harmony with the paradigm of JCPDS. The XRD study confirms that the consequential particles are nanoparticles. Still, it also confirms so as to the synthesized nanoparticles are gratis of impurities as no other description XRD peaks were observed. The mean grain crystalline size of green synthesized tungsten nanoparticles was calculated using the Debye- Scherrer formulaD $=\mathrm{K} \lambda / 6 \cos \theta$ where $\mathrm{D}$ is the average crystalline diameter size $(\AA), \mathrm{K}$ is a constant $(0.9), \chi$ is the wavelength of the $X$-ray used $(\mathrm{k}=1.54 \AA)$, ' $\beta$ ' is the angular line width[63] at the half maximum of diffraction (radians) and ' $\Theta$ ' is the Bragg's. The diffraction peaks at $22.08^{\circ}, 28.21^{\circ}, 30.13^{\circ}, 39.21^{\circ}, 41.35^{\circ}, 42.27^{\circ}, 51.02^{\circ}, 64.09^{\circ}, 71.02^{\circ}$, and $80.25^{\circ}$ can be indexed to (100), (111), (101), (121), (200), (222), (001), and (110), crystal planes of tetragonal WNPS (JCPDS card No. 46-1043). The crystal phase of the biosynthesized $\mathrm{SnO}_{2}$ NPs was analyzed using XRD. Figure $3 \mathrm{c}$ shows the XRD pattern of the biosynthesized SnNPs, which exhibits a series of well-defined diffraction peaks. The diffraction peaks at $27.05^{\circ}, 37.21^{\circ}$, $48.99^{\circ}, 52.02^{\circ}, 54.19^{\circ}, 58.05^{\circ}, 61.89^{\circ}, 65.06^{\circ}, 65.74^{\circ}, 69.21^{\circ}, 72.01^{\circ}$ and $78.98^{\circ}$ be capable of indexed to (110), (200), (111), (211), (311) and (321) crystal planes of cubic $\mathrm{SnO}_{2}$ (JCPDS card No. 41-1445). Moreover, the XRD pattern of the biosynthesized $\mathrm{SnO}_{2} \mathrm{NPs}$ also presents the peak at $27.05^{\circ}, 37.21^{\circ}$ and $48.99^{\circ}$, which is analogous to the carbon signals. As mentioned above, the continuation of carbon is likely to originate from the organic encapsulation of SnNPs. The green synthesized PbNPs is analyzed using XRD. Figure 4c, shows the XRD pattern of the biosynthesized PbNPs, which exhibits a sequence of well-defined diffraction peaks. The diffraction peaks at $30.05^{\circ}, 38.21^{\circ}, 48.99^{\circ}, 58.05^{\circ}, 62.89$ and $64.98^{\circ}$ are indexed to (111), (110), (102), (002), (001), (200) and (121) crystal planes of crystalline cubic PbNPs (JCPDS card No. 04-0784). Furthermore, the XRD pattern of the biosynthesized PbNPs also presents the peak at $30.05^{\circ}$ and $38.21^{\circ}$. As mentioned before, the existence of carbon is probable to instigate from the organic encapsulation of PbNPs.

\subsubsection{SEM analysis}

The SEM uses a beam of high-energy electrons to fabricate a collection of signals at the exterior of specimens used. The signals demonstrate in sequence about the sample as well as chemical composition, and crystalline structure, external morphology (texture) and compass appraisal of materials which build up the illustration. SEM analysis is in wide-ranging precise to be non-destructive since the X-rays spawn do not pilot to loss of volume of the mock-up, so it becomes possible to frequently investigate the same materials. A scanning electron microscope is a category of electron microscope which images a sample by scanning it using a high-energy electron beam. The electrons then cooperate with the atoms making up the sample, consequently producing signals which divulge in sequence regarding the sample's opus, surface topography and other properties such as electrical conductivity.

The SEM analysis is used to resolve the structure of the reaction products that are fashioned. Thin films of the sample are equipped on a gold coated copper lattice by just dipping a very small amount of the taster on the net, extra solution was removed using a blotting paper and then the film on the SEM grid are endorsed to dry by putting it under a mercury lamp for 5 minutes. SEM image has showed individual tungsten particles as well as a quantity of aggregates. SEM analysis is done to envisage outline and size of nanoparticle. The SEM image of synthesized tungsten nanoparticles (WNPs) are shown in figure 5. From the SEM images are 
seen in diverse intensification ranges like $5 \mu \mathrm{m}-50 \mu \mathrm{m}$ which clearly demonstrated the presence of rod shaped nanoparticles.
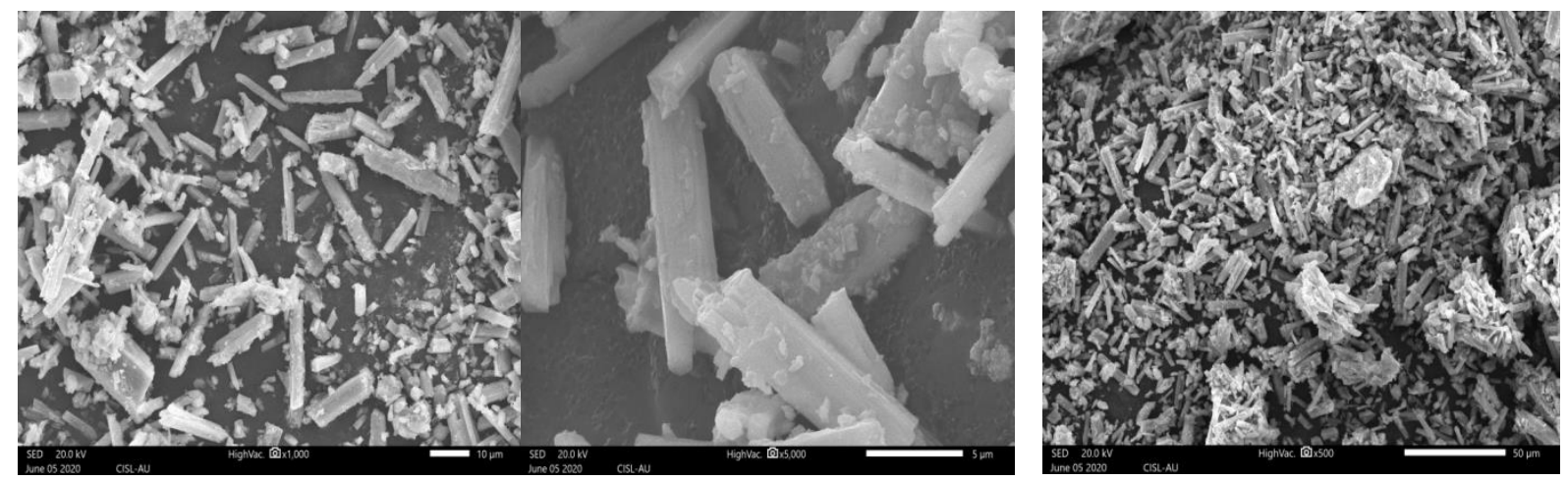

Figure:5 SEM images of Tungsten Nanoparticles(WNPs)
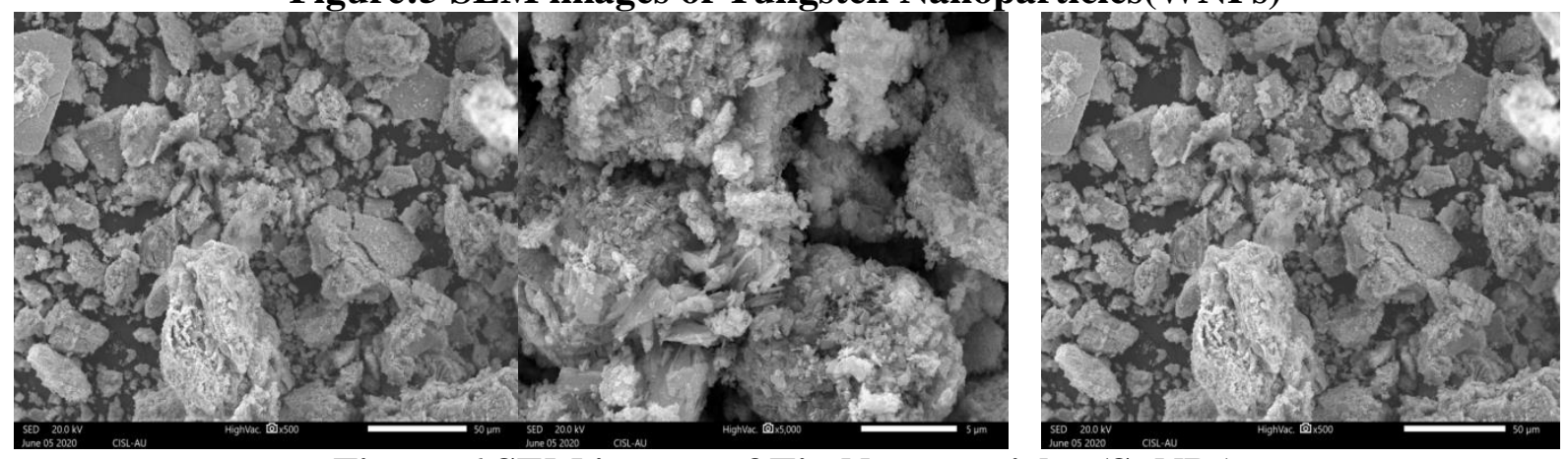

Figure:6 SEM images of Tin Nanoparticles (SnNPs)
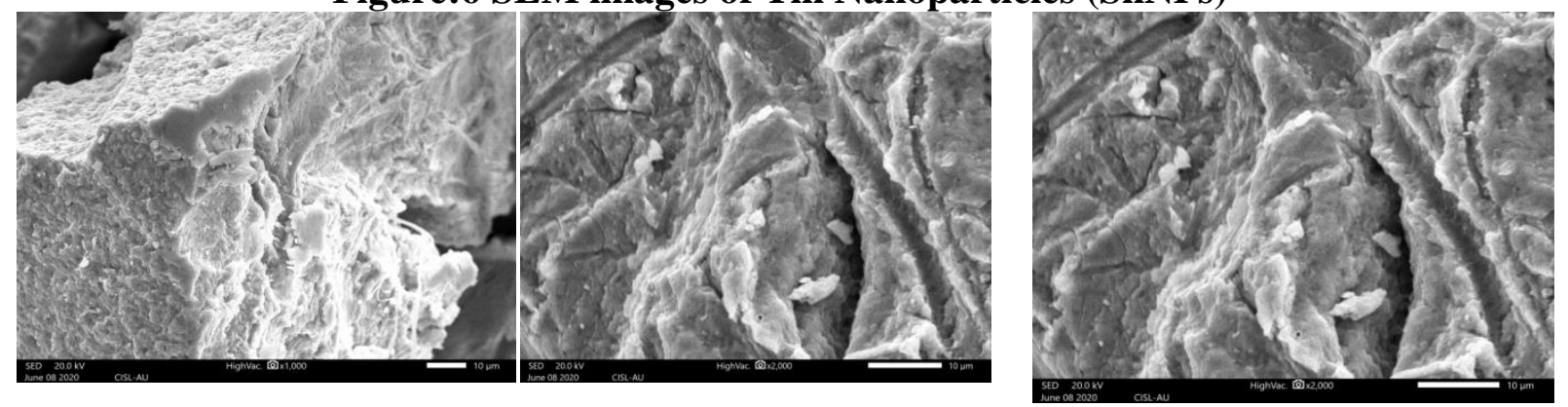

Figure:7 SEM images of Lead Nanoparticles (PbNPs)

The SEM analysis is used to conclude the structure of the reaction products that are formed. Thin films of the sample are equipped on a gold encrusted copper grid by just plummeting a very small amount of the sample on the grid, extra solution was removed by means of a blotting paper and then the film on the SEM grid are sanctioned to dry by putting it under a mercury lamp for $5 \mathrm{~min}$. SEM image has showed individual tin particles as well as a number of aggregates. SEM analysis is completed to dream of shape and size of nanoparticle. The SEM images of synthesized tin nanoparticles are shown in figure 6. The SEM images are seen in different magnification ranges like $10 \mu \mathrm{m}-50 \mu \mathrm{m}$ which clearly demonstrated the presence of spherical and mountain rock shaped nanoparticles.

The SEM analysis is used to determine the structure of the reaction products that are formed. Thin films of the sample are prepared on a gold coated copper grid by just dropping a very small amount of the sample on the grid, extra solution was removed using a blotting paper and then the film on the SEM grid were allowed to dry by putting it under a mercury lamp for 5 minutes. SEM image has showed individual zinc particles as well as a number of aggregates. 
SEM analysis is done to visualize shape and size of nanoparticles. The SEM image of synthesized lead nanoparticles is shown in figure 7. The SEM images are seen in different magnification ranges likes $10 \mu \mathrm{m}-50 \mu \mathrm{m}$ which clearly demonstrated the presence of thick mountain rock shaped nanoparticles.

\subsubsection{EDX analysis}

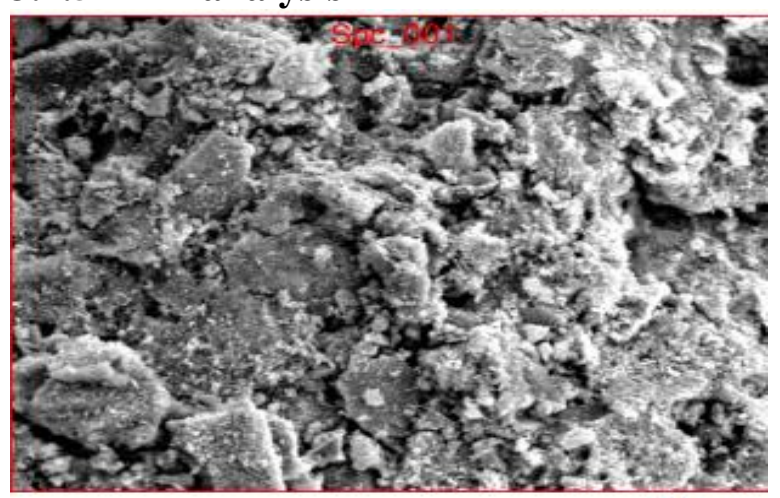

Fig 8a: EDX Image of WNPs

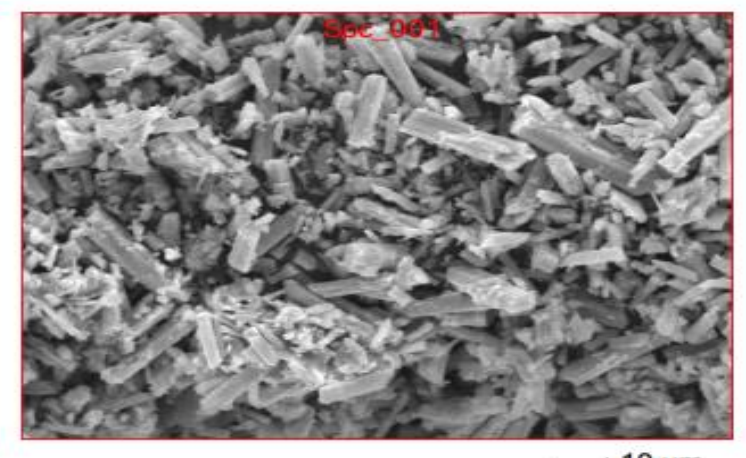

Fig 9a: EDX Image of SnNPs

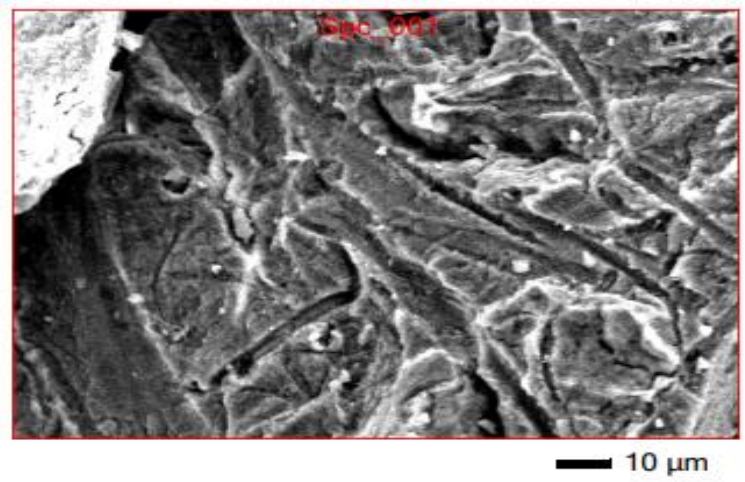

Fig 10a: EDX Image of PbNPs

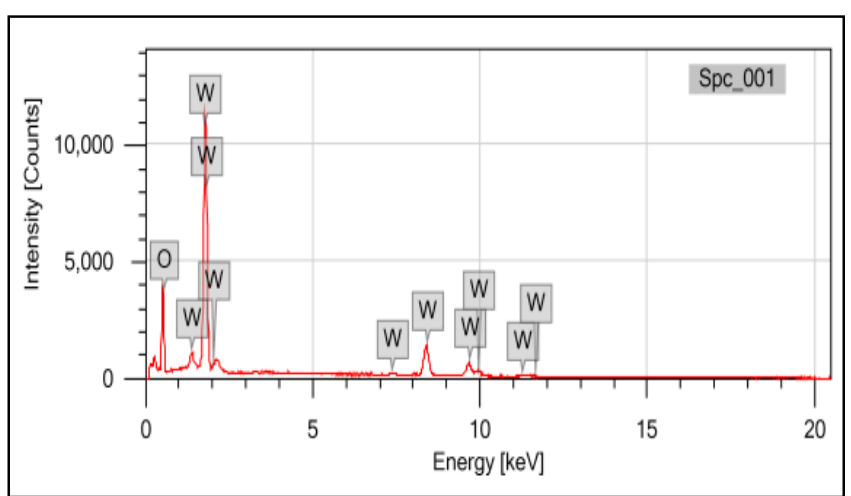

Fig 8b; EDX spectrum of WNPs

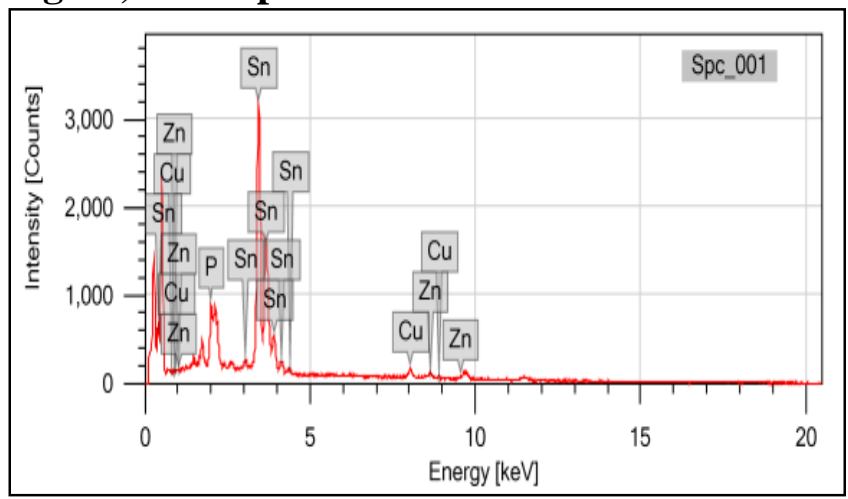

Fig 9b; EDX spectrum of SnNPs

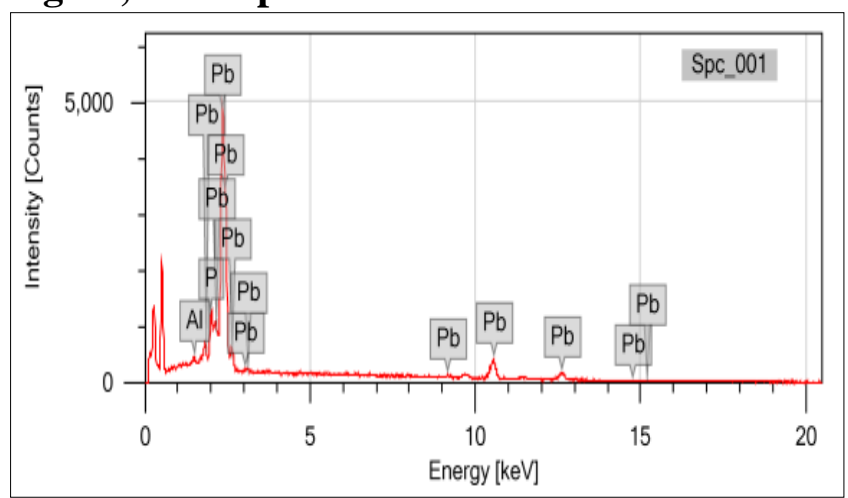

Fig 10b; EDX spectrum of PbNPs

The elemental information of biosynthesized WNPs is analyzed by EDX. As shown in the figure $8 \mathrm{a}$, evident that particle size is $10 \mu \mathrm{m}$. The intensive peak signals of $\mathrm{O}$ and $\mathrm{W}$ are observed in the spectrum (figure $8 \mathrm{~b}$ ) indicating the composition of $\mathrm{W}$ and $\mathrm{O}$. Besides, which could due to the biomolecules on the surface of the biosynthesized WNPs. The elemental information of biosynthesized SnNPs was analyzed by EDX. Figure 9a, reveals that particle size is $10 \mu \mathrm{m}$ and the intensive peak signals of $\mathrm{P}, \mathrm{Cu}, \mathrm{Zn}$ and $\mathrm{Sn}$ are observed in the spectrum figure 
$9 \mathrm{~b}$, indicating the composition of $\mathrm{Sn}$ and O. Besides, the spectrum also exhibits the existence of $\mathrm{C}, \mathrm{Na}$ and $\mathrm{P}$, which could due to the biomolecules on the surface of the biosynthesized SnNPs. The elemental information of biosynthesized PbNPs is analyzed by EDX and is shown in the figure $10 \mathrm{a}$, reveal that particle size is $10 \mu \mathrm{m}$. The intensive peak signals of $\mathrm{P}, \mathrm{Al}$ and $\mathrm{Pb}$ are observed in the spectrum (figure 10b) indicating the composition of $\mathrm{P}, \mathrm{Al}$ and $\mathrm{Pb}$. Besides, the spectrum also exhibits the existence of $\mathrm{P}, \mathrm{Al}$ and $\mathrm{Pb}$, which could due to the biomolecules on the surface of the biosynthesized PbNPs.

\section{ANTIMICROBIAL STUDIES}

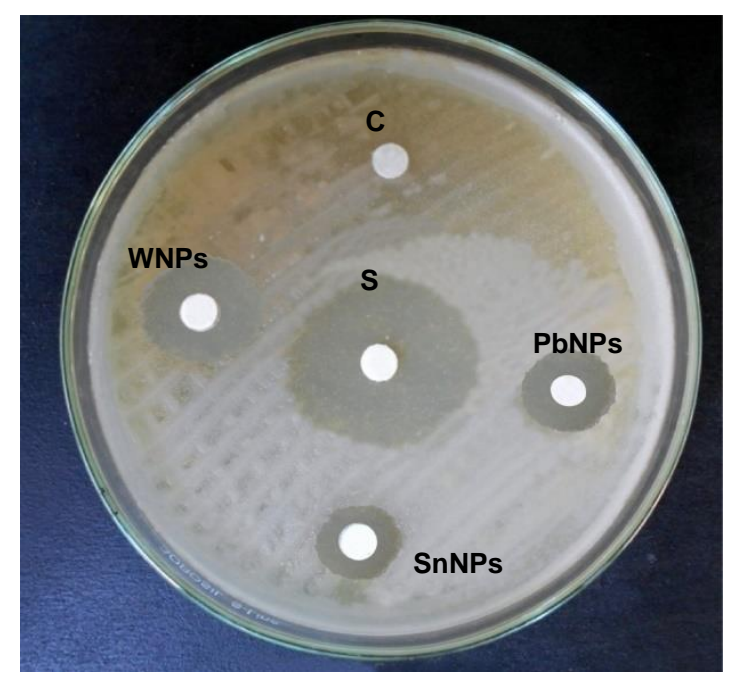

S. aureus

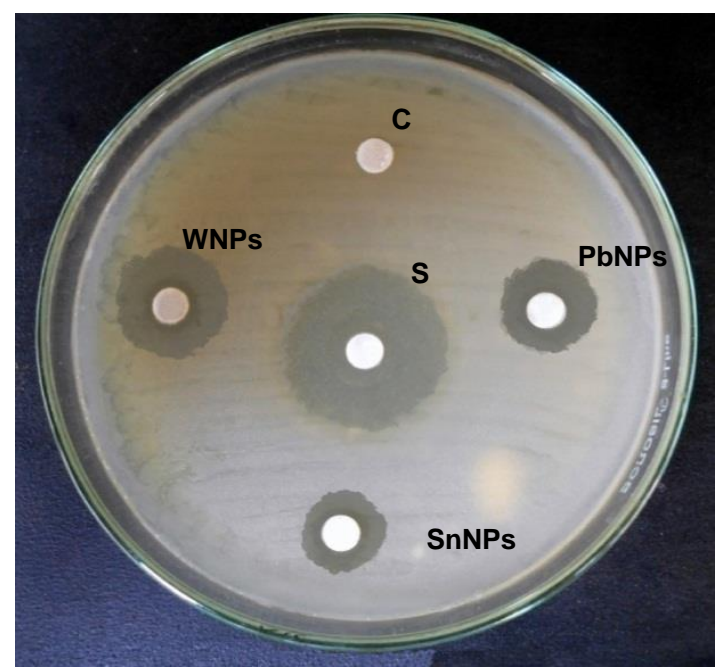

B.subtils

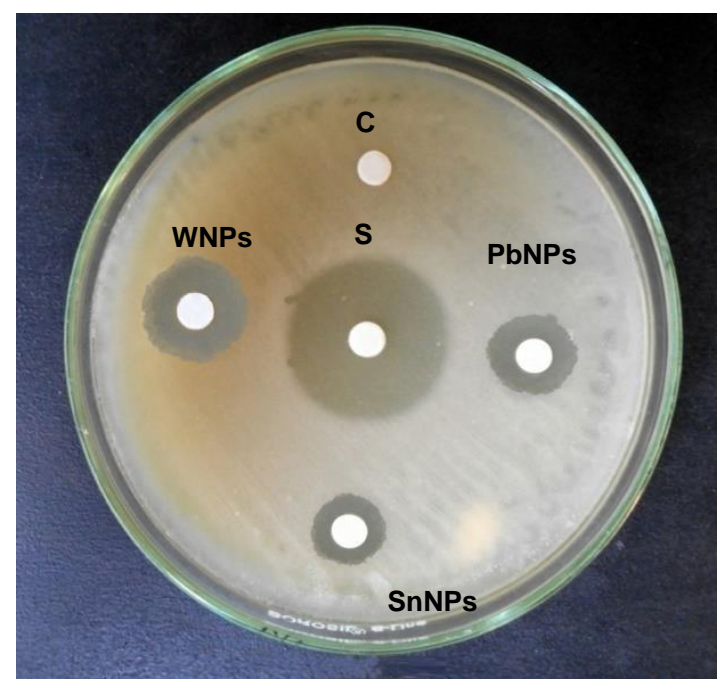

S. pyogenes

Figure:11. Plate of Antibacterial activities of WNPs, SnNPs and PbNPsagainst Gram positive Bacterial strains 


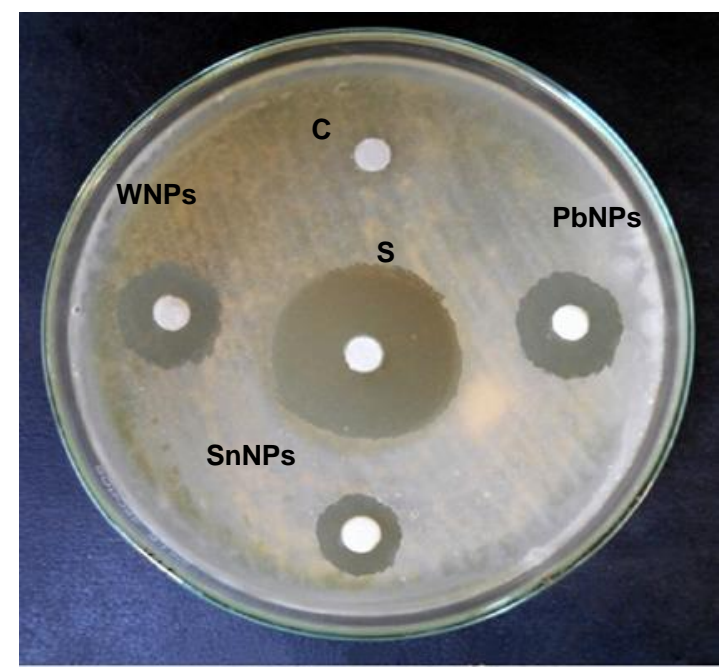

K. pneumonia

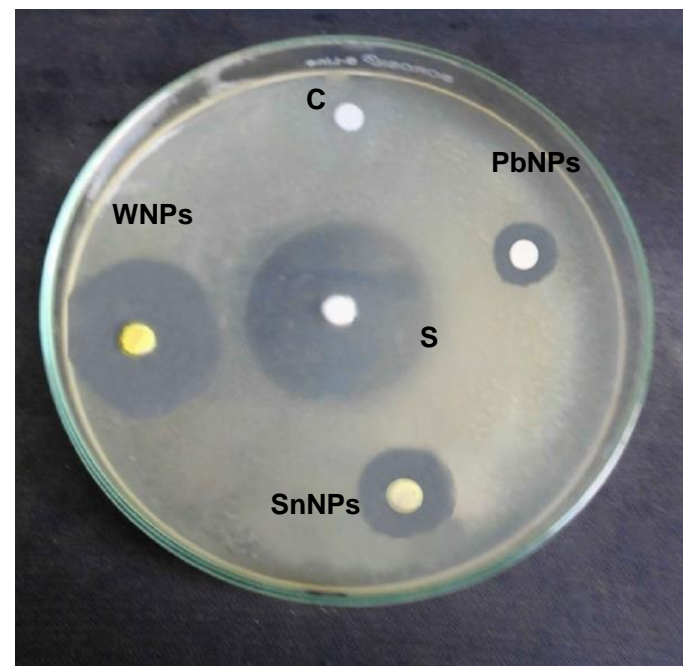

K. oxytoca

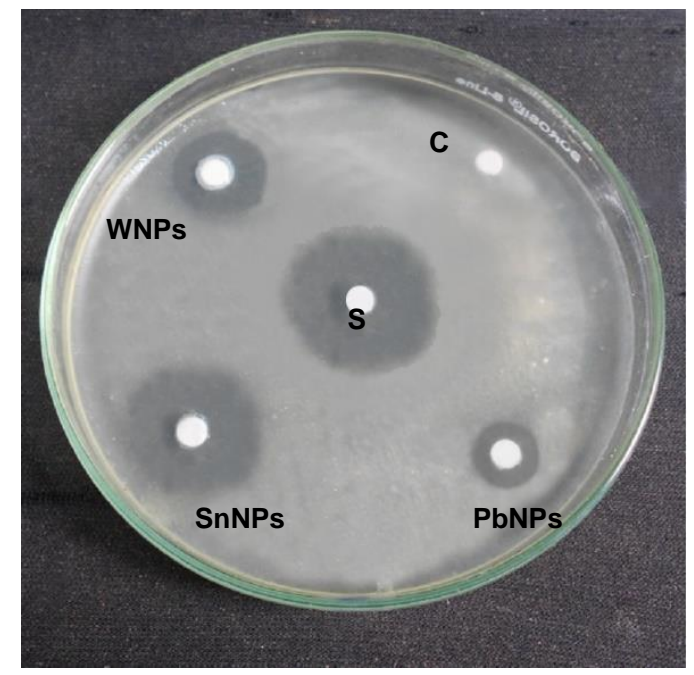

V.parahaemolyticus

Figure:12. Plate of Antibacterial activities of WNPs, SnNPs and PbNPs against Gram Negative Bacterial strains

The nanoparticles of WNPs, SnNPs and PbNPs mediated by aqueous extract of cucurbita maxima (pumpkin) flower are taken. The test solutions are prepared by $100 \mathrm{mg} / \mathrm{ml}$ of by dissolving the nanoparticles in pure dimethylsulfoxide (DMSO) (Sigma, USA-Pondy). Test organisms are collected from the Bacteriology Unit of (CAS) Central advanced studies of Marine biology in (Parangipettai) Annamalaiuniversity, Tamil Nadu. The organisms used in this research are three Gram positive (S. aureus and S. pyogenes, B.subtilis) and three Gram negative bacterial strains, (K. pneumonia , K. oxytoca, $V$. parahaemolyticus). Upon receipt, all isolates are subcultured onto selected culturing media to ensure purity and confirm their identification. The strains are maintained and tested on Mueller Hinton Agar (MHA) (Merck, Germany), which was stored at $4{ }^{\circ} \mathrm{C}$. The test organisms are cultured overnight at $37^{\circ} \mathrm{C}$ before being used in the antibacterial assay described below. 
The WNPs, SnNPs and PbNPs are tested same concentrations for antibacterial activity using the disc diffusion method [33]. Sterile commercial blank discs (Oxoid), $6.0 \mathrm{~mm}$ diameter, were impregnated with test solutions of WNPs, SnNPs and PbNPs. Discs were stored at $-5^{\circ} \mathrm{C}$ prior to use. During the night broth cultures are adjusted using at urbidometer to yield approximately 1.0 X $10 \mathrm{cfu}$ per ml. Nanoparticles impregnated discs $(20 \mu \mathrm{l})$ are placed on agar plates and incubated at $37^{\circ} \mathrm{C}$ for 24 hours. Pure DMSO $(20 \mu \mathrm{l})$ was used as a negative control, while ciprofloxacin discs $(30 \mu \mathrm{l})$ are used as a positive control. Antibacterial activities are then determined by measuring the clear zone of inhibition to the nearest millimetre ( $\mathrm{mm})$. An in vitro test for antibacterial activity revealed that WNPs, SnNPs and PbNPs mediated by the cucurbita maxima (Pumpkin) flower. The WNPs have shown good antibacterial effect against GPB (Gram positive bacterial) strains S.aureus, B. subtills and S. pyogenes while SnNPs have shown less activity and PbNPs have shown moderate antibacterial activity comparing standard ciprofloxacin. Gram negative Bacterial (GNB) strain of K.pneumoniae with WNPs shows moderate activity, PbNPs have shown good activity, poor activity against SnNPs. The gram negative bacterial strain of $K$. oxytoca demonstrated poor activity with WNPs, PbNPs and good activity SnNPs. V.parahaemolyticus a gram negative antibacterial strain have shown good activity towards SnNPs, moderate activity against WNPs and PbNPs have shown poor activity comparing standard ciprofloxacin. Table.3 shows zone of inhibition values of WNPs, SnNPs and PbNPs against gram positive and gram negative bacterial strains. Figure 11 and 12 expose the images of zone of inhibition plates of gram positive and negative bacterial strain against WNPs, SnNPs and PbNPs, respectively, Figure:13 have shown in the cluster column chart of WNPs, SnNPs and PbNPs against bacterial strains

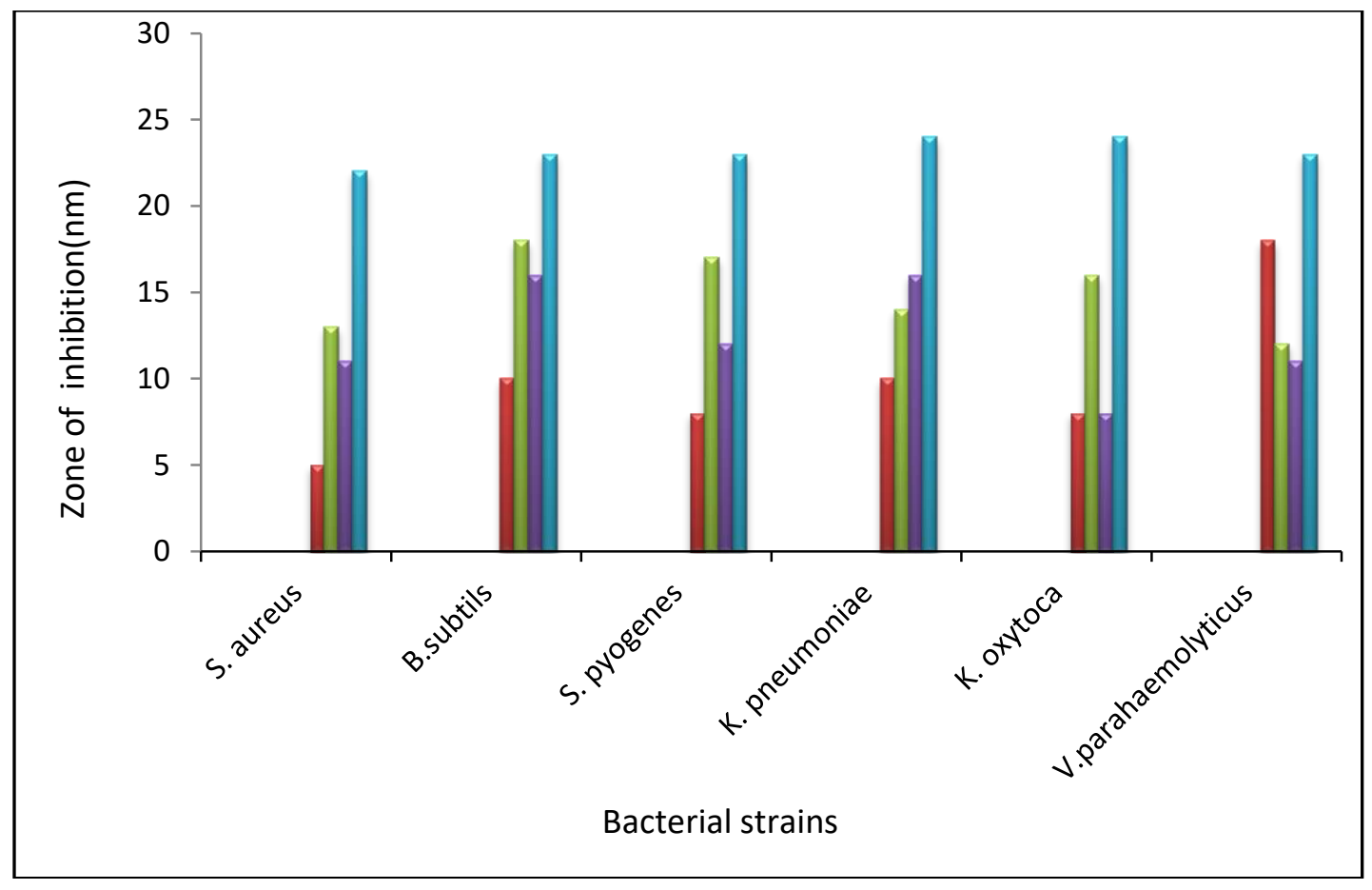

Figure:13. The Cluster column chart of WNPs, SnNPs and PbNPs against bacterial strains 
Table: 3 Zone of inhibition on Antibacterial activities of WNPs, SnNPs and PbNPs against Gram positive and Gram negative Bacterial strains

\begin{tabular}{|c|c|c|c|c|c|c|}
\hline \multirow[b]{3}{*}{ 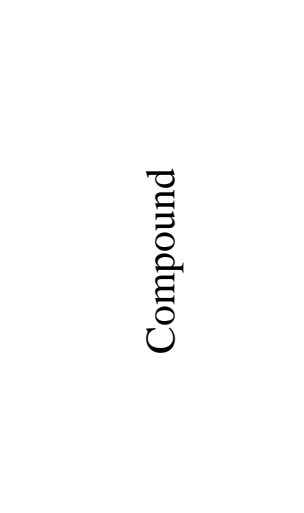 } & \multicolumn{6}{|c|}{ Zone of Inhibition (mm) } \\
\hline & \multicolumn{3}{|c|}{ Gram positive Bacteria } & \multicolumn{3}{|c|}{ Gram negative Bacteria } \\
\hline & 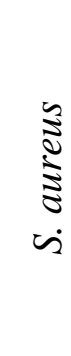 & 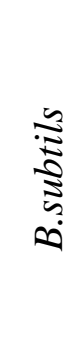 & 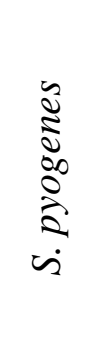 & 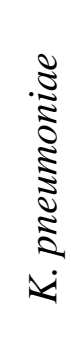 & 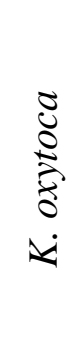 & 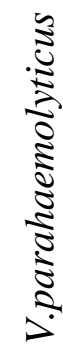 \\
\hline SnNPs & 5 & 10 & 8 & 10 & 8 & 18 \\
\hline WNPs & 13 & 18 & 17 & 14 & 16 & 12 \\
\hline PbNPs & 11 & 16 & 12 & 16 & 8 & 11 \\
\hline ciprofloxacin & 22 & 23 & 23 & 24 & 24 & 23 \\
\hline Control (DMSO) & - & - & - & - & - & - \\
\hline
\end{tabular}

\section{CONCLUSION}

The green synthesis of WNPs, SnNPs and PbNPs nanoparticles by cucurbita maxima (pumpkin) flower extract was studied. The reduction of the metal charged ions led to the pattern of metal nanoparticles of fairly well-defined dimensions using the extract. Further, antibacterial activity of metal nanoparticles synthesized cucurbita maxima (pumpkin) flower extract has been explored. This green chemistry approach towards the synthesis of metal nanoparticles such as WNPs, SnNPs and PbNPs has many advantages such as environmental friendly, cost effective and it can be easily scaled up to large scale synthesis. Antibacterial studies of three metal nanoparticles on human being pathogen open a door for a fresh variety of antibacterial agents.

\section{REFERENCE}

[1] H.Agarwal,S.V.Kumar, S. Rajeshkumar,. A review on green synthesis of zinc oxide nanoparticles - an eco-friendly approach. Resour. Effic. Technol. 3, (2017)406413.

[2] M.Fazal-Ur-Rehman, 2018. Novel applications of nanomaterials and nanotechnology in medical sciences-a review.J. Basic Appl. Sci. Res. 8 (4) (2018) 11-22.

[3] S.Taheriniya, Z.Behboodi, Comparing green chemical methods and chemicalmethods for the synthesis of titanium dioxide nanoparticles. Int. J. Pharm. Sci. Res. 7 (12)(2016) 4927-4932.

[4] V.V.Makarov, A.J.Love, O.V.Sinitsyna, S.S.Makarova, I.V.Yaminsky, M.E.Taliansky, N.O.Kalinina, Green nanotechnologies: synthesis of metal nanoparticles using plants. ActaNaturae., 6 (1)(2014) 35-44

[5] H.Mirzaei, M.Darroudi, Zinc oxide nanoparticles: Biological synthesis and biomedical applications. Ceram. Int. 43 (1)(2017) 907-914. 
[6] M.Shah, D.Fawcett, S.Sharma, S.Tripathy, G.Poinern,,Green synthesis of metallic nanoparticles via biological entities. Materials 8 (11) (2015) 7278-7308.

[7] S.Hasan, A review on nanoparticles: their synthesis and types biosynthesis: mechanism. Res. J. Recent. Sci. 4(2015) 9-11.

[8] B.Malaikozhundan, Pharmaceutical applications of zinc oxide nanoparticles a review. Acta Sci. Pharm. Sci. 2 (1)(2018) 11-12.

[9] V.Srivastava, D.Gusain, Y.C.Sharma,. Synthesis, characterization and application of zinc oxide nanoparticles (n-ZnO).Ceram. Int. 39 (8) (2013) 9803-9808.

[10] K.S.Siddiqi, A.urRahman, A.Husen, Properties of zinc oxide nanoparticles and their activity against microbes. Nanoscale Res Lett. 13 (1) (2018) 1-13.

[11] M.Shaik, M.Khan, M.Kuniyil,A.Al-Warthan, H.Alkhathlan, M.Siddiqui, S.Adil, Plantextract-assisted green synthesis of silver nanoparticles using Origanum vulgare L. extract and their microbicidal activities. Sustainability., 10 (4) (2018) 913-927.

[12] A.Stephen, S.Seethalakshmi, Phytochemical synthesis and preliminary characterization of silver nanoparticles using hesperidin. J Nanosci.,(2013)1-7

[13] G.Marslin, K.Siram, Q.Maqbool, R.Selvakesavan, D.Kruszka, P.Kachlicki, G.Franklin, Secondary metabolites in the green synthesis of metallic nanoparticles. Materials. 11 (6), (2018) 940-948.

[14] S.Mourdikoudis, R.M.Pallares, N.T.Thanh, Characterization techniques fornanoparticles: comparison and complementarity upon studying nanoparticle properties. Nanoscale 10 (27) (2018) 12871-12934.

[15] A.M.Fayaz, K.Balaji, M.Girilal, R.Yadav, P.T.Kalaichelvan, R.Venketesan., Biogenic Synthesis of silver nanoparticles and their synergistic effect with antibiotics: A study against gram-positive and gram-negative bacteria. Nanomed.Nanotechnol. Biol. Med., 6, (2010) 103-109.

[16] S.Gómez-Graña, M.Perez-Ameneiro, X.Vecino,I.Pastoriza-Santos, J.Perez-Juste, J.Cruz, A.Moldes., Biogenic synthesis of metal nanoparticles using a biosurfactant extracted from corn and their antimicrobial properties. Nanomaterials, 7(2017) 139-153.

[17] K.B.Narayanan, N.Sakthivel, Biological synthesis of metal nanoparticles by microbes. Adv. Colloid Interface Sci., 156(2010) 1-13.

[18] J.L.Gardea-Torresdey, J.G.Parsons, E.Gomez, J.Peralta-Videa, H.E.Troiani, P.Santiago, M.J.Yacaman,Formation and growth of Au nanoparticles inside live alfalfa plants. Nano Lett., 2(2002) 397-401.

[19] J.LGardea-Torresdey, E.Gomez, J.R.Peralta-Videa, J.G.Parsons, H.Troiani, M.JoseYacaman, A.Alfalfa sprouts: A natural source for the synthesis of silver nanoparticles. Langmuir, 19(2003) 1357-1361

[20] A.T.Harris, R.Bali, On the formation and extent of uptake of silver nanoparticles by live plants. J. Nanopart. Res., 10(2008) 691-695.

[21] R.G.Haverkamp, A.T.Marshall, The mechanism of metal nanoparticle formation in plants: Limits on accumulation. J. Nanopart. Res., 11(2009) 1453-1463.

[22] K.H.Roh,B.K.Kwak, J.B.Kim, K.R.Lee, H.U.Kim, S.H.Kim,The influence of silver thiosulfate and thidiazuron on shoot regeneration from cotyledon explants of Brassica napus. J. Plant Biotechnol., 39(2012) 133-139.

[23] R.Kumari, J.S.Singh, D.P.Singh., Biogenic synthesis and spatial distribution of silver nanoparticles in the legume mungbean plant (Vignaradiata L.). Plant Physiol. Biochem., 110 (2017) 158-166. 
[24] P.C.Vengaiah, B.Vijayakumari and P.Kiranmayi. Green synthesis Antimicrobial and Antioxidant effects of silver nanoparticle using CanthiumCoromandelicum leaves extract. IAJPR.,(2015) 1030-1033.

[25] E.Wallis,S.B.Gokhate , C.E.Kokate , Dr. Pulok and K.Mukherjee. Nutrients Composition of seed, Chemical Characterization and fatty acid composition of Oil of Syzygiumaromaticum. IJAC.,6(3)(2010)363- 366

[26] J. O. Tijani , O. Ugochukwu, L. A. Fadipe, M. T. Bankole, A. S. Abdulkareem\& W. D. Roos., One-step green synthesis of $\mathrm{WO}_{3}$ nanoparticles using Spondiasmombin aqueous extract: effect of solution $\mathrm{pH}$ and calcination temperature Appl. Phys. A., 125, 162 (2019). https://doi.org/10.1007/s00339-019- 2450-y

[27] Hu.Junjie, Biosynthesis of $\mathrm{SnO}_{2}$ Nanoparticles by Fig (FicusCarica) Leaf Extract for Electrochemically Determining $\mathrm{Hg}(\mathrm{II})$ in Water Samples.,Int. J. Electrochem. Sci., 10 (2015) 10668 - 10676

[28] N. Gandhi, D. Sirisha and SmitaAsthana., Microwave Mediated green synthesis of lead $(\mathrm{Pb})$ nanoparticles and its potential applications, IJESRT., 7(1): January, (2018) 623644

[29] McMurry, Organic Chemistry, 2nd Edn, Pacific Grove, USA (1988).

[30] J. L. Rios, M. C .Recio, Medicinal Plants and antimicrobial activity. Jr. of ethnopharmacology., 100, (2005) 80-84.

[31] M. F. Balandrian, A. F. Kjocke, and E. Wurtele., Natural Plant Chemicals: sources of industrial and mechanical material. Science., 228 (1985) 1154-1160.

[32] S.Poompozhil and D.Kumarasamy., studies on phytochemical constituent of some selected mangroves., JAIR.,2(10)(2014) 590-592

[33] A.W. Bauer, W. M. M. Kirby, J. C. Sherris and M. Turck, Antibiotic susceptibility Testing by a Standardized Disk Method., Am. J. Clin. Pathol.,, 45(1966) 493-496. 